\title{
Eles existem: a participação indígena na política eletiva
}

\author{
Adriane dos Santos Tavella Ferrari ${ }^{1}$
}

Ana Crhistina Vanali

\begin{abstract}
RESUMO: Este artigo tem por objetivo analisar a participação dos indígenas na política brasileira desde a década de 1970 até os dias atuais. Para tanto, um banco de dados dos candidatos eleitos foi construído e, com ele, foi possível apresentar um balanço da participação dos indígenas nas eleições, sobretudo da esfera municipal e analisar o perfil dos eleitos a partir de dimensões sociais e econômicas, tais como etnia, idade, estado civil, escolaridade, profissão e filiação partidária. Os resultados marcam uma participação indígena muito baixa se comparada com as outras etnias. Em que pese certa abertura e incentivo no sentido de maior participação dos indígenas na vida política-partidária, essa participação está muito aquém do seu contingente populacional, como nos revelam os dados.
\end{abstract}

Palavras-chave: Indígenas na política. Política e etnia. Mário Juruna.

\section{They exist: indigenous participation in elective politics}

\begin{abstract}
This article aims to analyze the participation of indigenous people in Brazilian politics from the 1970s to the present day. In order to do so, a database of the elected candidates was constructed and, with it, it was possible to present a balance of the indigenous participation in the elections, especially of the municipal sphere and to analyze the profile of those elected from social and economic dimensions such as ethnicity , Age, marital status, schooling, profession and party affiliation. The results mark a very low indigenous participation compared to other ethnic groups. In spite of some openness and encouragement in the sense of greater participation of indigenous people in political-party life, this participation is far below their population, as the data reveal.
\end{abstract}

Keywords: Indigenous people in politics. Politics and ethnicity. Mário Juruna.

- Enviado em 01/05/2017

- Aprovado em 17/05/2017

${ }^{1}$ Graduada em Ciências Sociais pela Universidade Federal do Paraná. Especialista em Antropologia Social pela PUC-PR. Uma versão preliminar desse texto foi apresentada no VIII Seminário Nacional de Sociologia e Política realizado de 17 a 19 de maio de 2017 na UFPR.E-mail: adrianeferrari2045@gmail

2 Graduada em Ciências Sociais pela Universidade Federal do Paraná. Uma versão preliminar desse texto foi apresentada no VIII Seminário Nacional de Sociologia e Política realizado de 17 a 19 de maio de 2017 na UFPR.E-mail: anacvanali@yahoo.com.br 


\section{INTRODUÇÃO}

Este trabalho tem por objetivo analisar a participação dos indígenas na política brasileira desde a década de 1970 até os dias atuais. A década de 70 e início dos anos 80 são marcados pela efervescência dos Movimentos Indígenas em toda a América Latina. No Brasil, esse movimento acontece com as Assembleias Indígena, convocadas por diversas lideranças indígenas, com o objetivo em comum de serem ouvidos pelas autoridades nacionais. Como resultado desse movimento as lideranças indígenas passam a participar do cenário político brasileiro. Esta participação é marcada pela eleição com o primeiro vereador indígena do Brasil Ângelo Cretã (1976) no município de Manguerinha (PR) pelo partido ARENA(Aliança Renovadora Nacional), com 170 votos.

Para compreender melhor esse cenário do início do anos 70 até os dias de hoje será, construído, um banco de dados dos candidatos eleitos e, com ele, será possível apresentar um balanço da participação dos indígenas nas eleições, sobretudo da esfera municipal e analisar o perfil dos eleitos a partir de dimensões sociais e econômicas, tais como etnia, idade, estado civil, escolaridade, profissão e filiação partidária.

Os resultados permitirão analisar a participação indígena nas eleições brasileiras. Até o momento os estudos anteriores demonstram uma participação muito baixa se comparada com as outras etnias. Em que pese certa abertura e incentivo no sentido de maior participação dos indígenas na vida político-partidária, essa participação está muito aquém do seu contingente populacional, como nos revelam os dados levantados até o momento. 


\section{OBJETIVOS}

1. Demonstrar a participação indígena no campo político brasileiro

2. Destacar as principais lideranças indígenas nesse campo

3. Levantar o perfil do indígena eleitor e do indígena candidato e eleito

\section{METODOLOGIA}

1. Revisão da literatura

2. Dados do TSE (Tribunal Superior Eleitoral) - repositório dados eleitorais

3. Dados do TRE (Tribunal Regional Eleitoral) de cada estado

4. Dados da FUNAI

5. Dados de outras instituições que trabalham como a CMI (Conselho Missionário Indígena), ISA (Instituto Sócio-Ambiental), sindicatos e partidos políticos

6. Legislação petinente

7. Entrevista com as lideranças indígenas do Paraná

8. Análise da trajetória de Angelo Cretã e Mário Juruna 


\section{CONSIDERAÇÕES FINAIS}

- participação indígena no campo político não é recente, MAS não é frequente

- até 2014 TSE não registrava o item "cor/raça": dificuldade mapeamento retroativo

- Pouca literatura sobre o assunto

\section{REFERÊNCIAS}

- BICALHO, Poliene Soares dos Santos (2010). Protagonismo indígena no Brasil: movimento, cidadania e direitos (1970-2009). Brasília: Doutorado em História UNB.

- CASTRO, Paulo Afonso de Souza (2011). Angelo Cretã e a retomada das terras indígenas no sul do Brasil. Curitiba: Mestrado em Antropologia UFPR.

- COSTA, Tiemi e CODATO, Adriano (2014). As candidaturas indígenas nas eleições gerais de 2014. Curitiba: Observatório das elites políticas e sociais do Brasil, V.1, N.6, dezembro.

- FUNAI (2000). Breve cronologia da vida do Xavante Mário Juruna. Brasília: Projeto Memória Oral do Indigenismo no Brasil.

-FURTADO FILHO, Cid (2011). Mário Juruna: um marco na história dos povos indígenas. IN: Brasileiros de Raíz, V.1, N.4, outubro/novembro, p. 8-10.

- ISA (1982). Aconteceu: povos indígenas no Brasil. Brasília: Acervo ISA.

- JURUNA, Mario (19820. O gravador do Juruna. Porto Alegre: Mercado Aberto.

- LOBATO, Tiemi; CODATO, Adriano e CASTRO, Andrea (2014). Yasuana yamaramunha se anamaitá (vamos lutar, parentes): as candidaturas indígenas nas eleições de 2014. Caxambu: 39 ANPOCS. 